\title{
Porque eu Prefiro a Cirurgia Convencional no Tratamento das Varizes Tronculares (Safenas) dos Membros Inferiores
}

Naves B. ${ }^{1}$

${ }^{1}$ Belo Horizonte - Brasil.

E-mail: brunonaves1957@gmail.com

Naves, B. 2013. Porque eu Prefiro a Cirurgia Convencional no Tratamento das Varizes Tronculares (Safenas) dos Membros Inferiores, p.71. In: Bastos, Francisco Reis. Anais do V Simpósio Internacional de Flebologia [Blucher Medical Proceedings n.1 v.1]. São Paulo: Blucher, 2014

http://dx.doi.org/10.5151/medpro-flebo-SIF_44

\section{Introdução}

O tratamento Cirúrgico das Varizes apesar de bem conhecido ainda é desafiador.Nos últimos anos novas técnicas de tratamento das safenas tem aparecido e sido empregadas com grande sucesso.

\section{Discussão}

O trabalho consiste na apresentação de casos clínicos, demostrando que na maioria dos casos de tratamento das varizes tronculares(safenas) a cirurgia de varizes convencional é o tratamento mais indicado, mais eficiente e de melhor custo-benefício no Brasil, na atualidade. Nossa apresentação é embasada em uma ampla revisão de literatura que comprova a efetividade da técnica por longos períodos, comparando a cirurgia com as outras técnicas de controle das varizes de membros inferiores.

\section{Conclusão}

Reconhecemos a importância e efetividade das demais técnicas no tratamento das varizes da safena, mas a cirurgia de Varizes convencional continua uma ótima alternativa para grande maioria dos pacientes.

Palavras-chave: Varizes, cirurgia de varizes, IVC. 